\title{
LA CLAUSURA: MORADA PERPETUA
}

\author{
Closure: perpetual abode
}

\section{Ana María Martínez de Sánchez*}

\section{Resumen}

La predicación cumplió un papel importante como medio de comunicación de ideas y promoción de comportamientos. La adhesión a un estado, como el consagrado, exigía un determinado modo de vivir. La palabra del concionador era uno de los momentos esperados, tanto por las jóvenes que habían optado por la vida religiosa -en la toma de hábito, profesión o renovación de votos-, como por sus familiares y amigos que presenciaban aquel trascendental momento.

De los sermones estudiados -éditos e inéditos-, cinco pertenecen a Pantaleón García (1757-1827), tres a Miguel Calixto del Corro (1775-1851), uno a Estanislao Learte (1788-1858), y de cuatro se desconoce su autor, pero corresponden a fines del siglo XVIII y comienzos del XIX. El perfil establecido era uniforme aunque se dirigieran a diferentes órdenes religiosas -carmelitas y dominicas-, pues la base conceptual de los textos es que la salvación era más fácil alejándose del mundo, siempre que se verificaran los votos propios del estado y no desagradara cumplirlos.

$<$ Sermón $><$ Novicia $><$ Hábito $><$ Salvación $>$

\begin{abstract}
Preaching played an important role as a means of communicating ideas and promoting behaviors. Adhering to a state, such as consecration, demanded a certain way of life. The preacher's speech was one of the awaited-for moments, both for the girls who had opted for the religious life -at the moment of taking or renewing the vows- and their family and friends who witnessed this meaningful moment.

Among the studied sermons -published and unpublished-, five belong to Pantaleon García (17571827), three to Miguel Calixto del Corro (1775-1851), one to Estanislao Learte (1788-1858), and the authors of four of them are unknown but they correspond to the late eighteenth and early nineteenth century. The profile was uniformly set even when they were directed to different religious orders -Dominican and Carmelites-, since the conceptual basis of the texts is that salvation was easier being away from the world, provided that the vows were verified and that those who took them were not displeased to fulfill them.
\end{abstract}

$<$ Sermon $><$ Novice $><$ Habit $><$ Salvation $>$

Recibido: 10/05/2016 // Aceptado: 16/09/2016

\footnotetext{
Doctora en Historia. Jubilada de CONICET y UNC. Profesora de postgrado. Universidad del Salvador. marsan@arnet.com.ar
} 


\section{DOSSIER}

Martínez de Sánchez. La clausura: morada perpetua.

\section{Introducción}

La transmisión de la palabra a través de los sermones fue una de las herramientas fundamentales que la Iglesia católica utilizó para instruir y formar a los creyentes. En América cumplió un papel protagónico en la tarea evangelizadora y también para la conservación de la fe de los ya bautizados.

En el Río de la Plata, la oratoria sagrada constituyó una práctica común y extendida, ya que sus productos se encuentran mencionados en múltiples ocasiones, sea en forma de sermón, plática u oración -fúnebre o conmemorativa-. Las oportunidades concretas fueron las ceremonias del ciclo litúrgico regular, fiestas devocionales marianas o de los santos patronos y protectores de plagas o enfermedades, diferentes actividades de las cofradías, y numerosas celebraciones especiales -como la presentación de la Bula de la Santa Cruzada, el rezo de las 40 horas, los cumpleaños y onomásticas de los reyes, como también sus exequias y proclamaciones-. Éstas últimas fueron sustituidas, luego de las independencias, por misas de acción de gracias por triunfos en batallas libertadoras o aniversarios cívicos.

El lugar donde se predicaba podía ser cerrado, cuando se elegía el púlpito de las iglesias o un altar en las capillas, la sala de Profundis o el refectorio de los conventos; o abierto, cuando el espacio era una plaza o plazoleta frente a los monasterios y templos.

Aunque son abundantes los textos manuscritos que se han conservado de los siglos XVIII y XIX, en diferentes repositorios del actual territorio argentino, lamentablemente pocos son los que están fechados y se conoce el nombre de su autor ${ }^{1}$. Más allá de esta doble carencia se debe tener presente que existió un discurso unificado de la iglesia católica, con un valor universal a pesar de las diferencias de tiempo, espacio y autor.

Los sermones presentaban las pautas del “deber ser", estableciéndose paradigmas de comportamiento relacionados con las virtudes que se debían practicar y, por otro lado, los vicios que era necesario evitar para lograr la salvación, fin indiscutible en aquella época del paso por la vida terrena ${ }^{2}$.

El auditorio era homogéneo o variado, según la celebración convocada, como lo hemos demostrado en trabajos anteriores (Martínez de Sánchez, 2008 b, Clissa, 2008 y Berdini, 2013). A veces puede inferirse del propio texto, como por ejemplo cuando se hablaba a integrantes de cofradías -por las referencias puede saberse si era para los cofrades del Santísimo Sacramento o del Carmen-; al pueblo en general, si era una

${ }^{1}$ La ubicación cronológica puede soslayarse porque es posible datar los documentos, aproximadamente, en base a sus caracteres externos, como el tipo papel y sus filigranas, la tinta y el tipo de letra e, incluso, por datos que proporciona el propio texto. El desconocimiento sobre la autoría -a veces sólo atribuible a una u otra persona por los rasgos caligráficos y/o estilísticos-, impide conocer a ciencia cierta el nombre y apellido de quien lo compuso para realizar estudios puntuales, lo que permitiría analizar la formación y pensamiento de determinados concionadores. En ocasiones es factible atribuir la pluma al clero secular o regular y, en este caso, a una Orden concreta.

2 En relación a la temática se pueden consultar los artículos compendiados en tres libros dirigidos por Ana María Martínez de Sánchez (2008 a, 2013 y 2014). 
rogativa para que lloviera o la celebración de la fiesta del patrono San Jerónimo, o una plática para novicias, entre otras temáticas.

En esta oportunidad interesa conocer lo que se predicaba a las jóvenes que elegían la vida consagrada dentro de alguna orden religiosa, que en el caso de Córdoba fueron las carmelitas y las dominicas, Monasterios de San José o de Santa Catalina de Siena, respectivamente. Los textos permiten recorrer el periplo espiritual seguido por ellas, desde la toma de hábito y la profesión hasta la renovación de votos (de Cos, 2014).

\section{Fuentes}

Se ha trabajado sobre trece sermones éditos e inéditos. Los publicados corresponden: cinco a Fray Pantaleón García (1757-1827) y tres a Miguel Calixto del Corro (1775-1851) ${ }^{3}$. En cuanto a los inéditos, se estudiaron cinco que se conservan en el ex Instituto de Americanistas, denominado hoy: Colección Documental "Mons. Dr. Pablo Cabrera", Biblioteca Central "Elma Kolhmeyer de Estrabou" de la Facultad de Filosofía y Humanidades de la Universidad Nacional de Córdoba ${ }^{4}$. De éstos sólo conocemos de uno el autor, el Dr. Estanislao Learte, que fuera capellán y síndico de las carmelitas desde la década del 40 del siglo XIX.

En once textos es mencionada la orden a la que está destinado el sermón, las carmelitas del monasterio de San José, las dominicas de Santa Catalina de Siena en Córdoba, y uno a las capuchinas de Buenos Aires, en los dos restantes se desarrolla el tema pero sin brindar datos concretos de su carisma 5 .

Las temáticas se agrupan en renovación de votos, recepción y profesión de religiosas, el aniversario de la fundación de las Catalinas -todos de Córdoba- y una elección de priora capuchina en Buenos Aires.

3 Las citas de fuentes editas se colocan a pie de página ya que van unidas, en muchos casos, a citas de manuscritos inéditos, además de la complejidad que representa citar en el texto ciertos sermones que están ubicados en diferentes tomos pero corresponden a un mismo autor. Pantaleón García, Sermones panegíricos de varios misterios, festividades y santos, tomos III, IV y VI, Madrid, Imprenta de Collado, 1810. Tomo III: En la toma de hábito, pp. 289-303 y En la profesión de una religiosas, pp. 304-322. Tomo IV: De la visitación de Nuestra Señora y fundación del Convento de Monjas Catalinas de Córdoba del Tucumán, pp. 143-165. Tomo VI: En la Profesión de una religiosa, pp. 211-226 y En la recepción de dos religiosas Carmelitas, pp. 227-240. Miguel Calixto del Corro, Varios Sermones Panegíricos de las Principales Festividades de la Iglesia Católica, tomo I, Filadelfia, Impreso para el autor por T.K. y P. G. Collins, 1849. Plática sobre una profesión religiosa, pp. 141-163; Plática familiar sobre la renovación de votos de las Carmelitas Descalzas, pp. 165-182 y Segunda plática familiar sobre la renovación de votos, pp. 183-196.

4 Instituto de Estudios Americanistas (en adelante IEA), mantenemos la identificación tradicional de esta colección. docs. 11828 (Sobre elección de Prelada de las capuchina de Buenos Aires -1822), 11832 (Sobre carmelitas finales del XVIII), 11836 (Sobre carmelitas-1842), 11838 (Sobre profesión), 11839 (Sobre recepción de Monja Carmelita).

5 Tres de Pantaleón García se refieren a las catalinas y dos a las carmelitas, mientras que del Corro dedica dos de renovación de votos a las carmelitas y Learte, uno de profesión. 


\section{DOSSIER}

Martínez de Sánchez. La clausura: morada perpetua.

\section{El ser "mujer consagrada"}

Las motivaciones para ingresar a un convento fueron múltiples; desde una sincera vocación, hasta la elección de ese estado por razones económicas, sociales o personales, no siempre unidas a una inclinación estrictamente individual.

Dentro de los estados posibles de la persona en sociedad, uno fue la consagración religiosa, que durante varios siglos constituyó una expectativa generalizada para hombres y mujeres en el mundo católico, lo que llevó a que en algunas familias varios de sus miembros ingresaran en los conventos, sin olvidar a quienes enviudaban y elegían ese camino para continuar su vida (Fernández Fernández et al., 1997: 134).

Desde el púlpito, se consideraba a la mujer que se consagraba a Dios una "elegida" que abandonaba los valores mundanos -muriendo al siglo mediante "la renuncia"-, para desposarse con Jesucristo y dedicar el resto de su existencia a preparar su salvación eterna y ayudar, a través de la oración, a la de los demás (Martínez de Sánchez, 2010: 554) $)^{6}$.

Los concionadores comparaban la decisión de las jóvenes con la tarea que cumplió Moisés al conducir al pueblo israelita de Egipto hacia la liberación del Faraón, porque la elección del claustro como morada perpetua era considerada el modo de alejarse de toda tentación y de la maldad del mundo para estar protegidas junto a Dios ${ }^{7}$.

Los sermones hacen referencia a mujeres que destacaron en la vida religiosa, colocando sus nombres en plural -a la usanza de la escritura antigua- porque cada uno incluía el de todas las que las habían imitado: Catalinas de Cristo, Teresas, Gertrudis de Jesús, Jerónimas de la Concepción y Marianas de los Ángeles. Sobre ellas, dice García, se levantó el edificio místico de la casa de los Tejeda y los Fonseca, haciendo alusión a la fundación de doña Leonor de Tejeda de las catalinas de Córdoba (1613) y relaciona aquella fecha con la Visitación de María a Isabel. Destaca en ella tres acciones que la Virgen cumplió con su prima: caridad, falta de temor y misericordia. En aquel momento la joven de Nazaret mostró la caridad, como la tuvo Leonor con la ciudad de Córdoba; Isabel se libró del temor al parto, que es lo que el monasterio proporcionaba a las niñas al proporcionar una "casa de defensa", y se manifestó la misericordia, porque en ese "asilo de seguridad" se podían santificar las vírgenes (Arancibia y Ponza, 2014: 57) . Esa casa produjo frutos de santidad que el fraile enumera, fiel a la forma del plural que hemos comentado, refiriéndose a jóvenes que pertenecieron a ese convento: Marianas de la Cruz y de la Encarnación, Catalinas del Sacramento y de los Ángeles, Marías de la Purificación y del Rosario, Juanas de la Cruz y de Santo Domingo (Arancibia y Ponza, 2015). Esa gloria se propagó, además, a la fundación de las catalinas de Buenos

6 Learte insiste con la palabra "morir", "morid a los aplausos, honores, y a toda vanidad", "morid [...] a todos los bienes y riquezas del mundo", "morid a vos misma, y a vuestra propia voluntad". IEA, doc. 11836 fs. 10 v. y $11 \mathrm{r}$.

7 En el sermón dedicado a la Visitación y al aniversario de la fundación de las Catalinas (2 de julio de 1613), presenta a las religiosas como imitadoras de aquel pueblo elegido. García, Sermones panegíricos..., tomo IV, 1810, p. 143 y lo repiten los otros predicadores: IEA, doc.11836, f. 5 v. de Learte; y doc. 11832, f. $10 \mathrm{v}$. sin autor conocido.

8 García, Sermones panegíricos..., tomo IV, 1810, pp. 145 a 158. 
Aires, pues del monasterio cordobés salieron cinco religiosas que habitaron desde 1745 el edificio porteño9. A su vez actuaba como receptor de jóvenes, no sólo de la ciudad, sino también de otras partes del actual territorio argentino, como Jujuy, Salta, Tucumán, Santiago del Estero, La Rioja y Catamarca (González Fasani, 2011; Arancibia y Ponza, 2015).

Se consideraba que Dios era quien había elegido a cada doncella -entre una multitud de ellas-, para que se prepararan para el desposorio con el Señor.

Ingresaban primero como novicias, momento en el que tomaban el hábito. En las carmelitas se las aceptaba para ello en una primera votación. Pasados seis meses se hacía la segunda y a los diez la tercera que les permitía profesar, es decir, hacer los votos perpetuos una vez cumplido el año, momento en que realizaban la renuncia de sus bienes -habidos y por haber- de acuerdo a la Regla y a las Constituciones (Nieva Ocampo, 2008: 172). En las catalinas, la Priora tomaba examen, junto con las "madres del consejo" para que luego el obispo autorizara que se concretara la renuncia y le permitiera profesar (Martínez de Sánchez, 2010: 559, Nieva Ocampo y González Fasani, 2008 b: 232).

Pantaleón García explica que es la voz de Dios la que habla a cada joven para tomar la decisión y persistir en ella, como ya lo había hecho a Abraham, a Lot y a los Apóstoles y, dentro de su sexo a Clara, Inés, Teresa o Isabel, en el retiro de los monasterios. Por la "fuerza de la gracia", aquella joven que estaba por tomar su hábito, había escuchado, atendido y se había dejado invadir por vínculos sagrados, respondiendo a esa invitación sobrenatural. Aquel llamado la llevaba a abandonar a sus padres, según el mandato evangélico, para seguir a Dios, dispuesta a cumplir un eterno divorcio con el mundo (Martínez de Sánchez, 2010; Nieva Ocampo, 2009: 489) ${ }^{10}$.

De acuerdo al Salmo 82, Sor Bartolina de las Mercedes eligió "habitar en la casa de Dios, [antes] que morar en los tabernáculos del siglo"11, como también lo hicieron Venancia del Corazón de Jesús y Juana Manuela de San Agustín, todas en el monasterio de Santa Catalina ${ }^{12}$. En las carmelitas fue Estanislao Learte quien pronunció el sermón

9 Madre Ana María de la Concepción Arregui de Armaza y sores Gertrudis de Armaza, Catalina de San Laurel, Ana de la Concepción y María Josefa Narbona.

${ }^{10}$ IEA, doc. 11836, f. 2 r. García, Sermones panegíricos, En la profesión de una religiosa, tomo VI, 1810, p. 211. Conviene recordar la literatura de época -manuales y tratados- que explicaban las condiciones que debía cumplir una mujer consagrada, sus obligaciones y carismas. Para el caso de las dominicas escribieron, entre otros, Domingo de Valtanás, Exposición sobre el estado y velo de las monjas en 1557, obra publicada en Sevilla.

${ }^{11}$ En 1835 Bartolina de las Mercedes era la Priora del Convento de Santa Catalina de Sena y rubricó la Carta de Hermandad con las monjas carmelitas del convento de San José. Sor Bartolina profesó el 7 de mayo de 1795, en manos de la Madre Ana Hilaria del Sacramento. Su apellido era Villafañe y era natural de La Rioja. En 1830 fue elegida subpriora y priora en 1833 (Arancibia y Ponza, 2015: 130).

${ }^{12}$ Ambas eran Castillo de apellido, por lo cual Pantaleón García las califica en su sermón como "primicias" de la noble casa de los "Castillos". Naturales de Santiago del Estero profesaron el 20 de enero de 1792. Eran hijas del Coronel Antonio del Castillo y de doña Polonia Hernández. Ya lo habían hecho otras dos hijas en 1787, Brígida de Santa Lucía y María Josefa del Tránsito, y don Antonio solicitó en 1792 que ingresaran otras dos (Arancibia y Ponza, 2015: 128 y 129). Archivo del Monasterio Santa Catalina de Siena Córdoba (en adelante AMSC), Elección de priora y sucesos del trienio, tomo II, f. 165 y 166. Cabe 


\section{DOSSIER}

Martínez de Sánchez. La clausura: morada perpetua.

cuando profesó Rufina de Jesús, en el cual destacó la íntima alianza que se establecía entre la joven y su esposo, Jesucristo ${ }^{13}$.

Durante los siglos XVII y XVIII, y aún en el XIX, se escribieron muchas obras de ayuda para enfrentar diversos aspectos cotidianos, que iban desde la cura de enfermedades, el modo de preparar medicinas, las oraciones que se debían dedicar a un santo protector, el modo de ayudar a "bien morir" -literatura llamada del ars moriendi-, hasta textos que ilustraban sobre el modo de comportarse según el estado. En este sentido destacaron las obras de fray Antonio Arbiol, La familia regulada y La religiosa instruida. Ésta última la dedicó a la Virgen, por considerarla "amorosa madre de las fieles esposas de su Santísimo Hijo"14.

Los imprenteros solían reimprimir una obra que había sido exitosa, colocándole el año de la primera impresión para no tener que repetir los trámites de las licencias, aspecto que comprobó García Cuadrado que había sucedido con La religiosa instruida, obra que tuvo una difusión considerable (García Cuadrado, 2010: 56) ${ }^{15}$.

La imagen femenina que se presenta a las jóvenes que aspiran a ser novicias y luego profesar está unida no sólo a las virtudes de la Virgen María, sino especialmente a las principales santas del calendario católico. Ellas, humanas como las postulantes, pudieron en el silencio de los claustros alcanzar modos de perfección que fueron ejemplo para cada Orden.

Arbiol sostenía que los males que padecían los conventos se debían a ocho motivos principales: mala crianza de las novicias y jóvenes, falta de retiro y trato interior con Dios, mucha comunicación de los seglares, multitud de religiosas en un mismo convento (más de 40 entre legas y coristas consideraba que producían confusión), malas preladas que todo lo juzgaban con levedad alejándose de la Reglas y las Constituciones, "tráfagos y granjerías indignas" con que se veían atormentadas las buenas religiosas, muchos cumplimientos con el mundo (presentes, agasajos, gastos y pleitos) y falta de piedad y caridad con las enfermas y necesitadas. Contra esos ocho daños capitales

remarcar que García escribió un sermón para la toma de hábito como novicias, cuando tenían entre 16 y 20 años, y luego cuando hicieron los votos de profesión, superado el año de noviciado.

${ }^{13}$ Rufina Echenique era natural de Córdoba y el 2 de julio de 1841 tomó el hábito en el Monasterio de San José, hija de don Santiago Echenique y doña Petrona Becerra, ya fallecidos en aquel momento. Adquirió el nombre de Rufina Ignacia de Jesús a su ingreso en la orden carmelita. Archivo del Convento de San José (en adelante ACSJ), Libro de las elecciones de Prioras y demas oficios de este combento de Carmelitas descalsas, f. 126 r. La segunda votación se realizó a los seis meses de su ingreso, el 2 de enero de 1842, f. 127 v. y la tercera, y última, el 2 de mayo de 1842 al cumplir los diez meses de novicia. En 1859 era la priora del convento, cargo que desempeñó hasta 1865, volviendo a él en 1868, f. 141 r. En 1874 formaba parte del capítulo como clavaria, es decir quien custodiaba las llaves. Libro en el que se asientan los autos de visita que se han dado a este Monasterio de Carmelitas Descalzas y también las Actas de elecciones trienales, fs. 234 y 235. El obispo José Vicente Ramírez de Arellano hizo entrega de las Constituciones y de las llaves de la clausura a la nueva priora, tras una breve exhortación sobre el desempeño de su oficio y mandó que las religiosas la reconociesen como prelada electa. En 1862 fue elegida clavaria y en 1868 nuevamente priora, f. 242.

${ }^{14}$ La familia regulada se publicó por primera vez en 1713 y se realizaron varias ediciones. De La religiosa instruida, se registran ediciones en 1717, 1734, 1753, 1765, 1776 y 1791 durante el siglo XVIII.

15 Tres ediciones tiene pie de imprenta del mismo año, pero en realidad vieron la luz en años sucesivos. 
Arbiol trabajó en los ocho libros de que consta la obra: el primero trata de las novicias, el segundo de las jóvenes y la puntualidad de las religiosas en las comunidades, el tercero de los ejercicios espirituales, frecuencia de sacramentos y direcciones espirituales, el cuarto del trato doméstico regular de unas religiosas con otras, el quinto del modo de tratar a las personas de fuera del convento, el sexto de los oficios de la religiosas con excepción de la prelada, el séptimo de las obligaciones de la prelada y el octavo sobre las disposiciones de una religiosa instruida para bien morir (Arbiol, 1791 b).

El tratado de Arbiol se asemeja a los manuales de confesores o de penitentes que atendían a todas las situaciones que podían presentarse en la mente y el alma de las personas en las diferentes circunstancias. Quien siguiera ese texto tenía la hoja de ruta en sus manos, desde la tierna novicia, hasta la consolidada prelada, desde las prácticas cotidianas que debían cumplir hasta las acciones que tenían que evitar.

\section{Imágenes del discurso}

En los sermones se plasman expresiones que muestran aspectos positivos y negativos sobre el hecho de ingresar perpetuamente a los claustros de un monasterio. El concionador enaltece los primeros y justifica los segundos al considerar que esa alianza es una decisión prudente "pura, casta y santa" que lleva a una joven a separarse del mundo para ocultarse en la soledad de los claustros, ya que huir del mundo asegura la eterna felicidad, a imitación de la sabiduría demostrada por Salomón ${ }^{16}$.

El mundo es de temer porque "es el centro, domicilio, mansión y depósito de todos los males"17, donde se entretejen lazos y redes, de corrupción y malicia, mentiras y fraudes, infidelidad y perfidia. Cristianos como Agustín, Ambrosio, Crisóstomo, Nacianceno y también paganos como Platón, Sócrates, los Zenones y Séneca, sabían que el mundo brindaba placeres transitorios y los hombres, deslumbrados por bienes caducos, corrían hacia una ruina que no acababan de comprender. Quien ingresaba como religiosa evitaba todos esos riesgos, y por ello es justificable que Dios quitara del mundo a Santa Clara de Asís, Santa Teresa de Jesús, Santa Catalina de Sena, y a la gloriosa Santa Magdalena de Pazis, porque eran la más noble "porción del rebaño"18.

La riqueza, los placeres, honras y dignidades producían inquietudes y zozobras, mientras que el aborrecimiento del mundo conducía al amor que Dios tiene a los santos en el cielo, dicen García y Learte. Es reiterada la imagen en la que se contrapone el mundo terrenal lleno de ocasiones de pecado, donde es difícil vivir en santidad, frente a la calma que representa el claustro. Por esta razón, las jóvenes que ingresan no son dignas de compasión sino de envidia por parte de quienes quedan fuera. Ellas podrán dedicarse a la oración, la penitencia, los ejercicios espirituales y la meditación, lo que no es fácil estando en el mundo ${ }^{19}$.

${ }^{16}$ García, Sermones panegíricos..., En la profesión de una religiosa, tomo VI, 1810, p. 213.

${ }^{17}$ García, Sermones panegíricos..., En la profesión de una religiosa, tomo VI, 1810, p. 214.

${ }^{18}$ García, Sermones panegíricos..., En la toma de hábito de unas religiosas, tomo III, 1810, p. 289.

${ }^{19}$ García, Sermones panegíricos..., En la toma de hábito de unas religiosas, tomo III, 1810, p. 302. IEA, doc. 11832 , f. 2 r. y 11836 f. 2 r. 


\section{DOSSIER}

Martínez de Sánchez. La clausura: morada perpetua.

Por momentos el discurso penetra en un campo donde se intenta, además, convencer al auditorio, parientes y amigos de las profesantes, indicándoles que la opción elegida es la correcta, aunque los "mundanos" la cuestionen o no la aprueben ${ }^{20}$. Para justificar se recurre al ejemplo de los israelitas que, mientras se dejaron conducir eran felices y cuando quisieron usar de su libertad erraron. Tal vez el camino se percibía árido y triste, "con una soledad sombría y espantosa" pero es en medio de esas tribulaciones que Dios se manifiesta y esa adversidad hace nacer los santos en medio de las misericordias que el Señor aporta ${ }^{21}$. En suma, se enaltece la opción de la clausura.

Entre las imágenes positivas que se atribuyen al aislamiento se menciona el descanso, felicidad y despreocupación que proporciona el claustro. Puede ser que de vez en cuando les asalten pensamientos terrenales, pero el sosiego y la quietud, le darán "dones celestiales", "soberanos auxilios" y "gracias sobrenaturales" para sobrellevar cada instante.

El claustro supone candor y pureza, en el camino de la justificación y la santidad, porque mientras a otras jóvenes Dios las ha dejado flotando entre las aguas del mar, a ellas la ha retirado, rompiendo las ataduras del mundo, ya que es más difícil vivir en él que en el monasterio ${ }^{22}$.

El claustro es definido como una mansión de paz, tienda de seguridad y de confianza, porque en palabras de Isaías es un "asilo de dulzura y abundancia"23, mientas el mundo está lleno de maldades, el claustro está rebosante de bondades, como "rocíos en abundancia" y "lluvias que templan la amargura".

Para San Bernardo los aspectos positivos que logra una profesa son: libertad del espíritu, paz interior, piedad, alegría del corazón y posesión de los bienes que gozan los Bienaventurados en el cielo, es decir a Dios.

Refiriéndose específicamente a la religión carmelitana, consideran su claustro "respetable asilo", "dichosa soledad" y "amable retiro"24.

A cada voz negativa se le contrapone otra con carga positiva, referida al mismo objeto. El claustro es un desierto, pero también es rocío y lluvia y es soledad, pero a su vez entraña la compañía eterna de Dios.

Tanto García y Corro en sus escritos, como los de autor no identificado hacen referencia ejemplar a María y Marta, al dirigirse a las novicias. El ocio de la primera -que es un ocio especial- frente a los afanes de la segunda ${ }^{25}$. Por ello dice Corro: "Marta, Marta, tú te agitas, divides y ocupas de muchas cosas; mas advierte que una sola es la

${ }^{20}$ García, Sermones panegíricos..., En la toma de hábito de unas religiosas, tomo III, 1810, p. 301.

${ }^{21}$ García, Sermones panegíricos..., En la toma de hábito de unas religiosas, tomo III, 1810, p. 297.

${ }^{22}$ García, Sermones panegíricos..., En la toma de hábito de unas religiosas, tomo III, 1810, p. 292.

${ }^{23}$ Isaías, cp. 2, habla de la Jerusalén celestial, del Israel mesiánico que el predicador compara con el monasterio.

${ }^{24}$ IEA, doc. 11832 , fs. 5 r. y v.

${ }^{25}$ García, Sermones panegíricos..., En la toma de hábito de unas religiosas, tomo III, 1810 p. García, Sermones panegíricos..., En la recepción de dos religiosas Carmelitas, tomo VI, 1810, p. 229. Corro, Varios Sermones Panegíricos..., Plática sobre una profesión religiosa, tomo I, pp. 157 y 158. 
necesaria, y que María en medio de su silencio y quietud, que te parece tan mal, ha elegido la mejor parte".

\section{Los votos}

Como el estado que más se asemejaba a Cristo era el consagrado, según lo manifestaban los concionadores de acuerdo a la concepción de la época, la decisión de querer ser religiosa era tomada como "justa y racional" 26 . Corro, en la tercera década del siglo XIX, se lamenta de que en esos días se creyera lo que sostenía "la filosofía", en cuanto era "un sistema abortado por la impiedad y sostenido por el orgullo". Había esparcido las ideas más "subversivas de la sana moral y religión”, ya que no había, para el nuevo pensamiento, más verdades que las que podían tocarse $\mathrm{y}$, por ende, la consagración religiosa era tomada sin la seriedad que el caso requería ${ }^{27}$. Por todo ello era necesario aferrarse, con ahínco, a los preceptos de San Pablo puesto que, expresa Corro vehementemente, no existe más religión verdadera que la que dejó Jesucristo y ella solamente puede proporcionar felicidad.

Pantaleón García, por pertenecer a una época anterior -pre independentista, cuando las nuevas ideas filosóficas anticatólicas aún no se habían extendido-, presenta otro tipo de discurso basado esencial y reiteradamente en los peligros del mundo y las bondades de la vida religiosa.

Los votos al momento de la profesión, y la renovación de ellos en ocasiones posteriores, dieron origen a discursos diferentes. Así se percibe el sermón de la toma de hábito y el de profesión de las hermanas Castillo. García profundiza en el segundo el compromiso que significaba reafirmar lo ya prometido. Igual actitud manifiesta Corro cuando habla en la profesión de Juliana y luego en su renovación, considerando este acto como un reaseguro de la fidelidad a la promesa ${ }^{28}$.

En ambas oportunidades los concionadores, conocidos o anónimos, hacen referencia a los votos de pobreza, castidad y obediencia, sumando el de clausura en la

${ }^{26}$ García, Sermones panegíricos..., En la toma de hábito de unas religiosas, tomo III, 1810, p. 162. El predicador hace un ataque frontal a las nuevas filosofía que ridiculizan la religión y recomienda que no se dejen "seducir y alucinar por la vana filosofía, por sus falacias y sofismas".

${ }^{27}$ Corro, Varios Sermones Panegíricos..., tomo I, p. 142.

${ }^{28}$ Doña María Juliana Tagle tomó el hábito el 2 de febrero de 1822 con el nombre de María Juliana de San José. Era natural de Jujuy hija de Don José Miguel de Tagle y de doña María Teresa de Basterra. El 2 de julio del mismo año, cumplidos los seis meses de su ingreso, se realizó la segunda votación y el 2 de diciembre la tercera, satisfechos los 10 meses, todo de acuerdo a las constituciones. En las elecciones para Priora de 1850, Juliana de San José recibió un solo voto. El 20 de abril de 1868 ingresó otra novicia en la vacante dejada por Juliana, por lo que inferimos que entre esas fechas había fallecido. Archivo del Convento de San José (en adelante ACSJ) Libro de las elecciones de Prioras y demas oficios de este combento de Carmelitas descalsas de la Señora Santa Thereza de Jesús, de Cordova, año de 1726 corre desde folio 1. Libro de votaciones para recivir Monja de velo negro, blanco, o donada; de las recepciones al avito quando le toman de las aprovaciones para la Profesión, y de la Profesión; da principio y corre en este mismo tomo desde el folio 50, fs. 112 r.-113 v. y f. 149 r. y Libro en el que se asientan los autos de visita que se han dado a este Monasterio de Carmelitas Descalzas y tambien Las actas de elecciones trienales de Prioras y demas oficialas, f. 224. 
renovación. Con los dos primeros, se sometían a la penuria de la pobreza -manifestada en la desnudez de Cristo- y a la guerra contra la carne y los placeres. Corro considera que hay tres clases de bienes: de fortuna, que corresponden a las riquezas temporales y del cuerpo, que los divide en el entendimiento y la voluntad, considerados como placeres de los sentidos y del alma. Todos ellos corresponden a las renuncias que hacen las jóvenes novicias al prometer sus votos ${ }^{29}$. La pobreza les protegería de vanos deseos, ayudadas por el velo -con todo su significado- que les impediría ver los objetos peligrosos y evitar la tentación del ocio.

El voto de obediencia era considerado el más difícil de cumplir ya que se traslucía en la sumisión y subordinación a la Prelada, a quien deberían imitar, porque la reproducción de ciertas conductas conducía a la perfección. Rezar no es bueno si ella no lo aprueba, dice García ${ }^{30}$. Esa subordinación llevará a la humillación que impedirá que triunfe el amor propio. Existía un disciplinamiento a la Regla y las Constituciones de cada Orden, pero también a los mandatos de la Priora, quien podrá ser áspera o benigna, política o rústica, prudente o indiscreta, genial o adversa, pero ellas juraban obedecerla hasta la muerte bajo pena del infierno.

Ese espacio de mortificación y renunciamiento sería vigilado por la celadora para evitar las tentaciones. Su función era proteger a las jóvenes, dirigirlas y conducirlas, indicándoles el camino correcto.

Dado ese grado de subordinación, la elección de la priora, era un hecho importante dentro de cada Orden ya que quien era favorecida con los votos de la mayoría del claustro debía cumplir funciones de madre, directora espiritual y administradora temporal. Sin duda se presentaban diferentes opciones, conforme a las aspiraciones de las monjas que ya llevaban cierto tiempo en el convento y por ello los sermones con ocasión de las elecciones conducían a la reflexión, tanto de quienes anhelaban al cargo como de quienes tenían que votar, pues la felicidad o la contrariedad de los tres años siguientes dependían de esa elección, además de la responsabilidad individual que significaba colocar una bolilla negra o una blanca para una u otra aspirante ${ }^{31}$.

Quien mejor estuviera preparada era quien debía tomar el compromiso de conducir a las demás compañeras de Orden, fueran de velo blanco o de velo negro, novicias o profesas, jóvenes o mayores. Se sumaban en este caso las circunstancias históricas generales, porque en 1822 (tiempo de la reforma religiosa rivadaviana), se estaban reduciendo los conventos y era necesario manejar con acierto el timón para perdurar. El predicador aconsejaba que las elecciones fuesen en paz y que debían votar a quien pudiera cumplir del mejor modo sus obligaciones, del mismo modo que Cristo había elegido a sus Apóstoles ${ }^{32}$.

${ }^{29}$ Corro, Varios Sermones Panegíricos ..., Plática sobre una profesión religiosa, tomo I, p. 151.

${ }^{30}$ García, Sermones panegíricos ..., En la recepción de dos religiosas Carmelitas, tomo VI, 1810, p. 230.

${ }^{31}$ Las prioras duraban tres años en su cargo y no podían ser reelegidas hasta pasado un período. IEA, doc. $\mathrm{N}^{\circ}$ 11828: Plática para el Capítulo de elección de Abadesa del Convento de Capuchinas de esta Ciudad de Buenos Aires dicha a la comunidad el día 12 de diciembre de 1822.

${ }^{32}$ IEA, doc. $\mathrm{N}^{\circ}$ 11828: Plática para el Capítulo de elección de Abadesa del Convento de Capuchinas de esta Ciudad de Buenos Aires dicha a la comunidad el día 12 de diciembre de 1822, f. 3 r. 
Una constante en todos los textos y en los diferentes momentos, es el destacar que Dios prefirió individualmente a cada una y, por haberlas elegido Él mismo, las conduce por los caminos de la religión y las socorre con su ayuda ${ }^{33}$. Quienes predicaban para las carmelitas agregaban a su reflexión las bondades del Monte Carmelo como lugar de perfeccionamiento.

Las citas a los Padres de la Iglesia, del Antiguo y del Nuevo Testamento están presentes en todas las alocuciones. San Jerónimo, San Bernardo, Santo Tomás, son mencionados como quienes en esa ocasión quieren que las jóvenes reciban un nuevo bautismo y con él, el Espíritu Santo, que les acompañará en ese desierto del claustro que las aleja de los peligros del mundo.

Al profesar se agregaba el voto de clausura, como hemos dicho, por el cual se sepultaban -en palabras del predicador- hasta la muerte en soledad ${ }^{34}$. El gran eje de la predicación es que esa muerte es la victoria, porque mueren anticipadamente por propia voluntad para alcanzar de modo menos perturbador, la salvación eterna.

En el momento en que van a hacer los votos renuncian por testamento irrevocable a todos sus bienes habidos y por haber, cambian el nombre -perdiendo el apellido- para tomar otro de profesión relacionado con el carisma de la Orden, se cortan el cabello, las campanas tocan a muerte y las oraciones son para difuntos. Todo este rito está profundamente imbuido de significados. La teatralización que se desarrolla pone en evidencia lo que significa la decisión tomada y muestra que para "los mundanos" no preocupa la muerte en sí, sino dejar los bienes que se poseen y los goces que se disfrutan.

La castidad y la clausura las separa para siempre de los placeres, porque de ese modo las protege de las diversiones y de los "espectáculos alegres" y de los "castos deleites del matrimonio", para asegurarles la vida eterna ${ }^{35}$. El predicador anónimo expresa que no puede dejar de hacer una apología eficaz, es decir que persuada, de lo que significa el desprendimiento de la joven que opta por ingresar a las carmelitas, y al respecto dice:

"Yo desenvolveré esas preocupaciones ilustradas con que el Mundo deshonra la práctica edificante de estos asilos de la Religión, y sobre que el enemigo del hombre ha derramado todo su veneno, principalmente entró los fanatismos de una nación infiel a un Dios, traidora a un Soberano y desconocida a sí misma"36.

Los votos significaban la reafirmación del modo elegido para evitar la muerte por el pecado, que les alejaba la salvación eterna, como lo que hizo Abraham sacando a

${ }^{33}$ Estos son los tres puntos que Pantaleón García desarrolla "En la toma de hábito de unas religiosas": elección, conducción y socorro, tomo III, 1810, pp. 289-303. IEA, doc. 11836, f. 2 r. Learte en profesión de Carmelita.

${ }^{34}$ García, Sermones panegíricos..., En la profesión de unas religiosas, tomo III, 1810, pp. 304-322.

${ }^{35}$ García, Sermones panegíricos..., En la profesión de unas religiosas, tomo III, 1810, p. 311. IEA, doc. 11832 y 11836, f. 2 v.

${ }^{36}$ IEA, doc. 11832, f. 1 r. 
su pueblo de Caldea, Jacob de Siria, Moisés del palacio de Faraón, Daniel de Babilonia, Elías de Judea, al Bautista de su patria. Salirse del mundo para librar el alma de la muerte.

Cuando han realizado los votos ya pueden considerarse felices, porque han pasado la prueba y con la práctica de la pobreza son superiores a los demás mortales, con la castidad felices como los Ángeles, por la obediencia dichosas a semejanza de Dios, no es una felicidad absoluta y consumada sino de una "felicidad principiada", pues se extenderá a toda su permanencia en el monasterio ${ }^{37}$.

La renovación de los votos, como sostiene Corro, es un grado más de perfección dentro del estado elegido, porque coloca a la joven en la situación de reafirmar lo que profesó. No sólo el necesario prescindir de la riqueza, del contacto carnal y obedecer, sino que además no debe sentirse molesta por no poseer esos bienes y deseos y estar dispuesta sin mortificación a cumplir con lo que la Prelada ordena ${ }^{38}$.

Fray Pantaleón se dirige a la madre de las jóvenes profesantes y le dice que se vista de Sara, no de desconfianza sino de alegría porque Venancia y Juana Manuela van a enriquecer su casa con bendiciones eternas, mientras los "mundanos" quedarán como espectadores de aquel sacrificio.

Todos los concionadores apuntan a la necesidad de practicar la constancia. San Bernardo decía que la tibieza era peor que el pecado, ya que de éste se podía retornar mediante el arrepentimiento, pero de la tibieza no se podía salir.

Todo es un combate en que el alma, sorprendida de los sentidos, padece una disipación de espíritu que impide contemplar las bellezas de la sabiduría. Después de ese combate se asciende a un cierto reposo en que sin distracción se goza de la verdad. De ese estado se pasa a una embriaguez que hace ignorar la propia existencia, momento en que, según Santa Teresa, comienza la divina locura ${ }^{39}$.

\section{Reflexión final}

Aunque entre los sermones de García y los de Corro median tres décadas, como con el de Learte, coinciden los argumentos que celebran la decisión de las jóvenes que toman el hábito o profesan y, la contracara se manifiesta en la lamentación por la situación del siglo. En Corro se vislumbra además la crisis política y la pérdida de valores religiosos. Sin embargo, son dos estilos muy diferentes, que podrían calificarse: de optimista el primero sobre las vocaciones que se originan en la sociedad cordobesa, mientras en Corro se detecta a un sacerdote apesadumbrado por los hechos que suceden en su entorno. Sin duda todos los textos, incluyendo los de autor desconocido, coinciden en el mensaje para el hecho concreto sobre el que les toca platicar, aunque se produzcan en momentos históricos diferentes.

\footnotetext{
${ }^{37}$ García, Sermones panegíricos..., En la profesión de unas religiosas, tomo III, 1810, p. 317.

${ }^{38}$ Corro, Varios Sermones..., Plática familiar sobre la renovación de votos de las Carmelitas Descalzas, pp. 166 y 167 y Segunda plática familiar sobre la renovación de votos, pp. 188 y ss.

${ }^{39}$ IEA, doc. 11832 , f. 10 r.
} 
Los escritos de fray Pantaleón García se asemejan a la literatura de la época -inmediata y anterior-, como por ejemplo el texto de Antonio de Arbiol, de corte más espiritual, pero que no desconoce el mundo real y material en el que todos están inmersos, con todos los vicios y defectos que precisamente son los que hay que sortear y superar.

Las monjas aunque estaban recluidas en sus claustros, también padecieron los vaivenes del mundo exterior y, en especial, las repercusiones de las luchas por la independencia y las crisis económicas que ellas conllevaron (Nieva Ocampo, 2012: 820; González Fasani, 2012: 806).

Corro se alegraba que, luego de tantos años donde se había confundido vicio $\mathrm{y}$ virtud, era saludable que hubiera una nueva vocación. Pero su queja resuena en sus sermones: ¡Qué impiedad! ¡Qué corrupción! ¡Qué desconcierto y aturdimiento! Exclama, contrariado por la época que le toca vivir ${ }^{40}$. Contra toda esa carga, que siente negativa para la fe, le toca predicar en el espectáculo edificante de la profesión religiosa de la hermana Juliana. La gracia está fuera de la razón humana y lo agradece, pero considera que no es lo mismo que gente ilustrada en la religión esté engreída con sus luces o seducidas por el espíritu de novedad que les inspira su ignorancia y se atrevan a desconocer el Evangelio.

Comparando unos con otros, los sermones dichos en las ocasiones referidas, no presentan mayor originalidad textual, más allá de que permean la situación de época.

Una joven deja el mundo y su familia para reunirse con otras que persiguen el mismo fin, salvar su alma para Gloria de Dios y bien de la sociedad, constituyéndose en ejemplos carnales de la posible santidad.

\section{Referencias Bibliográficas}

Arancibia, J.M y Ponza, C. O. 2014. Historia del Monasterio Santa Catalina de Siena de la ciudad de Córdoba por Religiosas del mismo Monasterio, dos tomos, Transcripción, presentación y notas de..., Córdoba, Gráficas Cervantes.

Arancibia, J.M y Ponza, C.O. 2015. Alabar, bendecir y predicar el amor de Dios. Tabla cronológica de las monjas del Monasterio Santa Catalina de Siena en la ciudad de Córdoba, (1613-1901), Córdoba, Gráficas Cervantes.

Arbiol, A. 1791 a. La familia regulada, con doctrina de la Sagrada Escritura y Santos Padres de la Iglesia Católica, Imprenta Real, Madrid.

Arbiol, A. 1791 b. La religiosa instruida, Madrid, Viuda de Marín.

Berdini, J. 2013. "Sermones, batallas y victorias. Providencialismo y patrocinio guerrero de la Virgen María en la homilética sagrada (1806-1812)”. En: Martínez de Sánchez, A.M. (Directora). Cátedra, púlpito y confesionario. Hacer y decir sermones, Córdoba, CIECS-UNC, pp. 75-99.

Clissa, K. 2008. "El valor de la confesión en sermones coloniales”. En: Martínez de Sánchez, A.M. (Compiladora). Oralidad y escritura. Prácticas de la palabra: los sermones, Córdoba, Programa de Estudios Indianos, Centro de Estudios Avanzados, CONICET-Universidad Nacional de Córdoba, pp. 97-118.

${ }^{40}$ Corro, Varios sermones..., Plática sobre una profesión religiosa, p. 142. 
Cos, J. de O.P. Editor. 2014. Antigua espiritualidad, liturgia y observancia de las monjas dominicas, Fanjeaux, S.H.O.P.

Fernández Fernández, A; Leiva Viacava, L; Guerra Martinière, M; Martínez Alcalde, L. 1992. La mujer en la conquista y la evangelización en el Perú (Lima 1550-1650), Lima, Pontificia Universidad Católica del Perú.

García Cuadrado, A. 2010. La librería en el siglo XVIII: el murciano Juan Polo Ruiz, Murcia, editum.

González Fassani, A.M. 2011. "El monasterio de San José de Córdoba del Tucumán espacio de devoción y de promoción social". En: Nieva Ocampo, G.; Benito Moya, S.G.A. y Navarro, A. (coord.), Servir a Dios y servir al Rey. El mundo de los privilegiados en el ámbito hispánico (ss. XIII-XVIII), Córdoba, El Mundo Editorial, pp. 141-163.

González Fassani, A. M. 2012. "El monasterio de San José: permanencias en un tiempo de crisis (1810-1825)". En: Cancino, H.; de la Mora, R.; Medeiros de Menezes, L. y Benito Moya, S.G.A. (Editores). Miradas desde la Historia social y la Historia intelectual. América Latina en sus culturas: de los procesos independentistas a la globalización, Córdoba, Centro de Estudios Históricos "Prof. Carlos Segreti", Universidad Católica de Córdoba, Universidad Veracruzana, pp. 805-818. E-Book.

URL: http://www.cehsegreti.org.ar/descargas/hugo-cancino.pdf

Martínez de Sánchez, A. M. 2008 a. Compiladora. Oralidad y escritura. Prácticas de la palabra: los sermones, Córdoba, Programa de Estudios Indianos, Centro de Estudios Avanzados, CONICET-Universidad Nacional de Córdoba.

Martínez de Sánchez, A. M. 2008 b. "El purgatorio. Visión y acción a través de los sermones de ánimas”. En: Martínez de Sánchez, A.M. (Compiladora) Oralidady escritura. Prácticas de la palabra: los sermones, Córdoba, Programa de Estudios Indianos, Centro de Estudios Avanzados, CONICET-Universidad Nacional de Córdoba, pp.119-141.

Martínez de Sánchez, A. M. 2010. "Morir al siglo: la renuncia en el Derecho Indiano". En: Guzmán Brito, A. (Editor). El Derecho de las Indias Occidentales y su pervivencia en los Derechos patrios de América, Tomo II, Valparaíso, Ediciones Universitarias de Valparaíso, pp. 547-568.

Martínez de Sánchez, A. M. (Directora) 2013. Cátedra, púlpito y confesionario. Hacer y decir sermones, CIECS, Córdoba.

Martínez de Sánchez, A. M. 2014. Algunos sujetos y objetos de la oratoria sagrada en América colonial. E-book URL: http://hdl.handle.net/11086/1706 Consultado el 23 de octubre de 2015.

Nieva Ocampo, G. 2008. "Servir a Dios con quietud: la elaboración de un modelo regular femenino para las dominicas castellanas a mediados del siglo XVI". En: Hispania Sacra, LIX, 119, pp. 163-196. 
Nieva Ocampo, G. 2009. “'Dejarlo todo por Dios, es comprar el cielo': el voto de pobreza, la mendicidad y el asistencialismo entre los dominicos castellanos (1460-1550)". En: Hispania Sacra, LXI, 124, pp. 483-512.

Nieva Ocampo, G. y González Fasani, A. M. 2008. "Virtud, honor y linaje: la dote como instrumento de exclusión social entre las dominicas de Córdoba del Tucumán a principios del siglo XVIII". En: Siegrist, N. (Coordinadora). Dotes, conflictos y divorcios en Buenos Aires, el Tucumán y otros territorios rioplatenses durante el periodo hispano, Buenos Aires, pp. 223-241.

Nieva Ocampo, G. 2011. "Elite social, facciones políticas y decadencia económica: el Monasterio de Santa Catalina de Córdoba del Tucumán entre 1810 y 1830". En: Cancino, H.; de la Mora, R.; Medeiros de Menezes, L. y Benito Moya, S.G.A. (Editores). Miradas desde la Historia social y la Historia intelectual. América Latina en sus culturas: de los procesos independentistas a la globalización, Córdoba, Centro de Estudios Históricos "Prof. Carlos Segreti”, Universidad Católica de Córdoba, Universidad Veracruzana, pp. 819-829. E-Book. URL: http://www.cehsegreti.org.ar/descargas/hugo-cancino.pdf 